Neuroepidemiology 2013;41:219-220

DOI: $\underline{10.1159 / 000354780}$

\section{Validation of Stroke Prognostic Scores: What Do Clinicians Need to Know?}

\author{
Gustavo Saposnik ${ }^{\mathrm{a}-\mathrm{d}}$ \\ ${ }^{\text {a }}$ Stroke Outcomes Research Unit, Stroke Outcomes Research \\ Canada, Division of Neurology, Department of Medicine, \\ St. Michael's Hospital and ${ }^{\text {b}}$ Department of Health Policy, \\ Management and Evaluation, Faculty of Medicine, University \\ of Toronto, 'Institute for Clinical Evaluative Sciences, and \\ ${ }^{\mathrm{d}}$ Li Ka Shing Knowledge Institute, Toronto, Ont., Canada
}

Prognosis is a medical term, derived from the Greek - foreknowing, foreseeing - to denote the likelihood of the occurrence of a particular outcome. In the last few years, several colleagues have developed stroke risk prognostic scores to predict different outcomes, including early and long-term mortality, disability, discharge disposition, response to tPA and risk of intracerebral hemorrhage after thrombolysis, among others [1-7]. When applied to large populations, risk scores can provide useful prognostic estimates.

Clinicians, patients and their families wonder about the probability of having a good outcome, response to an intervention, or risk of death and/or disability after an acute ischemic stroke.

The iScore (Ischemic Stroke Risk Score) is a validated score including several well-known factors affecting stroke outcomes (e.g. age, sex, stroke severity, glucose on admission, concomitant comorbid conditions, preadmission dependency, etc.) [8]. It can be used not only to estimate the risk of short- and long-term death and disability early after hospitalization for an acute ischemic stroke (www.sorcan.ca/iscore), but also the likelihood of achieving a favorable outcome after tPA and risk of intracranial hemorrhage $[9,10]$.

Béjot et al. [11] evaluated the performance of the iScore in over 1,000 stroke patients, applying a population-based design in France. They found good performance of the iScore when applied to their patients: the C-statistic was 0.85 (95\% CI: 0.82-0.89) for 30-day and $0.84(0.81-0.87)$ for 1-year mortality. Similar findings were observed for disability (C-statistic: $0.81,95 \%$ CI: $0.79-0.84$ ). They also found similar good discrimination for mortality (C-statistic: 0.85 , 95\% CI: $0.76-0.93)$ and for functional outcome at discharge (Cstatistic: $0.81,95 \% \mathrm{CI}: 0.72-0.90)$ for patients receiving tPA.

What Are the Limitations of the Study?

The sample size is relatively small. Despite this, however, the authors showed good performance when comparing the observed versus the predicted outcomes by the iScore when applied to a dif- ferent (other than the validated) population. It is also possible that other variables not included in the iScore may have influenced the observed outcomes.

What Are the Practical Implications for Clinicians?

First, since stroke is a syndrome with multiple mechanisms and broad implicated factors, the prediction of clinical outcomes after stroke constitutes a challenge.

Second, there are several risk scores (e.g. TPI, DRAGON, ASTRAL, SEDAN, SPAN-100) to predict clinical outcomes after stroke $[2-4,6,12]$. Clinicians need practical and validated tools in several ethnic groups when discussing prognosis with stroke patients and their families.

Third, a recent randomized study (JURaSSiC) revealed that the iScore improved clinicians' independent estimations of outcomes after stroke. For example, the overall clinician's accuracy for death or disability at discharge was $16.9 \%$ compared to $90 \%$ of the iScorebased estimates, which were within the $95 \%$ CI of observed outcomes [13].

Fourth, the application of clinical tools (available on the web or for smart phones) may help in communicating with and in counseling patients and their families [14]. In my personal view and as shown in the JURaSSiC trial, most stroke risk prediction outcome scores would facilitate, on average, better estimations compared to predictions based solely on the experience of clinicians [13].

Fifth, several authors attempted to compare different risk scores. They favored the use of some risk scores by comparing two statistical performance measures: discrimination and calibration. However, these measures have limited (if any) use for practical clinicians [15]. What we need to know is how many patients were 'correctly diagnosed' by each risk score in the general population and/or prespecified groups. Moreover, clinicians would like to know the probability of a good outcome or the risk of intracerebral hemorrhage predicted by each risk score after receiving tPA (compared to patients not receiving $\mathrm{tPA}$ ). It is important to bear in mind that calibration and discrimination are statistical measures of performance of models that provide limited information to answer the aforementioned questions.

Sixth, when applying risk scores it is important to evaluate their validity in the studied population (e.g. external validity or generalizability). For example, the iScore was initially created and validated in an ethnically diverse population from Canada [8]. More recently, studies from Greece, Korea, China and other countries revealed good performance in other ethnic groups [16-19]. The present study provides some additional evidence of its application to a welldefined European population [11]. Together, the aforementioned points illustrate some of the benefits, caveats and limitations for outcome predictions using risk scores. Paraphrasing Albert Einstein (March 14, 1879 to April 18, 1955): 'Occurrences in this domain are beyond the reach of exact prediction because of the variety of factors in operation, not because of any lack of order in nature.'

\section{KARGER}

(C) 2013 S. Karger AG, Basel

$0251-5350 / 13 / 0414-0219 \$ 38.00 / 0$
Dr. Gustavo Saposnik

55 Queen St East, Suite 931, St Michael's Hospital

University of Toronto

Toronto, ON M5C 1R6 (Canada)

E-Mail saposnikg@smh.ca 
Acknowledgments

Dr. Saposnik is supported by the Distinguished Clinician Scientist Award from the Heart and Stroke Foundation of Canada (HSFC).

\section{Disclosure Statement}

Dr. Saposnik declares no conflict of interest.

\section{References}

1 O’Donnell MJ, Fang J, D'Uva C, Saposnik G, Gould L, McGrath E, Kapra MK: The PLAN score: a bedside prediction rule for death and severe disability following acute ischemic stroke. Arch Intern Med 2012;172:15481556.

-2 Strbian D, Engelter S, Michel P, Meretoja A, Sekoranja L, Ahlhelm FJ, Mustanoja S, Kuzmanovic I, Sairanen T, Forss N, Cordier M, Lyrer P, Kaste M, Tatlisumak T: Symptomatic intracranial hemorrhage after stroke thrombolysis: the SEDAN score. Ann Neurol 2012;71:634-641.

- 3 Strbian D, Meretoja A, Ahlhelm FJ, Pitkaniemi J, Lyrer P, Kaste M, Engelter S, Tatlisumak T: Predicting outcome of IV thrombolysis-treated ischemic stroke patients: the DRAGON score. Neurology 2012;78: 427-432.

4 Kent DM, Selker HP, Ruthazer R, Bluhmki E, Hacke W: The strokethrombolytic predictive instrument: a predictive instrument for intravenous thrombolysis in acute ischemic stroke. Stroke 2006;37:2957-2962.

5 Konig IR, Ziegler A, Bluhmki E, Hacke W, Bath PM, Sacco RL, Diener HC, Weimar C: Predicting long-term outcome after acute ischemic stroke: a simple index works in patients from controlled clinical trials. Stroke 2008;39:1821-1826.

-6 Saposnik G, Guzik AK, Reeves M, Ovbiagele B, Johnston SC: Stroke Prognostication using Age and NIH Stroke Scale: SPAN-100. Neurology 2013;80:21-28.

7 Ntaios G, Faouzi M, Ferrari J, Lang W, Vemmos K, Michel P: An integer based score to predict functional outcome in acute ischemic stroke: the ASTRAL score. Neurology 2012:78:1916-1922.

-8 Saposnik G, Kapral MK, Liu Y, Hall R, O’Donnell M, Raptis S, Tu JV, Mamdani M, Austin PC: IScore: a risk score to predict death early after hospitalization for an acute ischemic stroke. Circulation 2011;123:739-749.
9 Saposnik G, Demchuk A, Tu JV, Johnston SC: The iScore predicts efficacy and risk of bleeding in the National Institute of Neurological Disorders and Stroke Tissue Plasminogen Activator Stroke Trial. J Stroke Cerebrovasc Dis 2013;22:876-882.

10 Saposnik G, Fang J, Kapral MK, Tu JV, Mamdani M, Austin P, Johnston SC: The iScore predicts effectiveness of thrombolytic therapy for acute ischemic stroke. Stroke 2012;43:1315-1322.

- 11 Béjot Y, Jacquin A, Daubail B, Durier J, Giroud M: Population-based validation of the iScore for predicting mortality and early functional outcome in ischemic stroke patients. Neuroepidemiology 2013;41:169-173.

12 Lou M, Safdar A, Mehdiratta M, Kumar S, Schlaug G, Caplan L, Searls D, Selim M: The HAT Score: a simple grading scale for predicting hemorrhage after thrombolysis. Neurology 2008;71:1417-1423.

13 Saposnik G, Cote R, Mamdani M, Raptis S, Thorpe KE, Fang J, Redelmeier DA, Goldstein LB: JURaSSIC: accuracy of clinician versus risk score prediction of ischemic stroke outcomes. Neurology 2013;81:448455.

14 Garg AX, Adhikari NK, McDonald H, Rosas-Arellano MP, Devereaux PJ, Beyene J, Sam J, Haynes RB: Effects of computerized clinical decision support systems on practitioner performance and patient outcomes: a systematic review. JAMA 2005;293:1223-1238.

15 Cook NR: Use and misuse of the receiver operating characteristic curve in risk prediction. Circulation 2007;115:928-935.

16 Park TH, Park SS, Ko Y, Lee SJ, Lee KB, Lee J, Kang K, Park JM, Choi JC, Kim DE, Cho YJ, Hong KS, Kim JT, Kim DH, Cha JK, Han MK, Lee JS, Yu KH, Lee BC, Yoon BW, Bae HJ, Saposnik G: The iScore predicts clinical response to tissue plasminogen activator in Korean stroke patients. J Stroke Cerebrovasc Dis, E-pub ahead of print.

17 Park TH, Saposnik G, Bae HJ, Lee SJ, Lee KB, Lee J, Park JM, Choi JC, Kim DE, Cho YJ, Kim JT, Cha JK, Yu KH, Lee BC, Yoon BW: The iScore predicts functional outcome in Korean patients with ischemic stroke. Stroke 2013;44:1440-1442.

18 Zhang N, Liu G, Zhang G, Fang J, Wang Y, Zhao X, Pan Y, Guo L: External validation of the iScore for predicting ischemic stroke mortality in patients in China. Stroke 2013;44:1924-1929.

19 Saposnik G, Reeves MJ, Johnston SC, Bath PM, Ovbiagele B: Predicting clinical outcomes after thrombolysis using the iScore: results from the Virtual International Stroke Trials Archive. Stroke 2013;44:2755-2759. 